\title{
DESAFIOS À EFETIVAÇÃO DO ACESSO À INFORMAÇÃO REFERENTE AOS DOCUMENTOS DO REGIME MILITAR EM FACE DOS SEUS NOVOS MARCOS NORMATIVOS
}

\section{Challenges to effective access to information concerning the documents of the military regime in the face of its new regulatory milestones}

\section{RogÉRIO GeSTA LEAL}

Doutor em Direito. Professor Titular da Unisc. Professor da Unoesc. Professor Visitante da Università Túlio Ascarelli - Roma Trè, Universidad de La Coruña - Espanha, e Universidad de Buenos Aires. Professor da Escola Nacional de Formação e Aperfeiçoamento da Magistratura (Enfam). Coordenador Científico do Núcleo de Pesquisa Judiciária, da Escola Nacional de Formação e Aperfeiçoamento da Magistratura (Enfam), Brasília. Coordenador da Rede de Observatórios do Direito à Verdade, Memória e Justiça nas Universidades brasileiras - Secretaria de Direitos Humanos da Presidência da República. Membro da Rede de Direitos Fundamentais - Redir e do Conselho Nacional de Justiça - CNJ, Brasilia. Membro do Conselho Científico do Observatório da Justiça Brasileira. Desembargador do TJRS.

\section{TAIS RAMOS}

Especialista em Direito Processual Civil da Universidade de Santa Cruz do Sul - Unisc. Mestranda em Direitos Sociais e Políticas Públicas pela mesma Instituição. Bolsista do Conselho Nacional de Desenvolvimento Científico e Tecnológico - CNPO. Integrante do Grupo de Pesquisa "Estado, Administração Pública e Sociedade", Projeto de Pesquisa: "Verdade, memória e justiça: análises da experiência das políticas públicas reparatórias do governo no Rio Grande do Sul envolvendo os atos de sequestro, morte, desaparecimento e tortura de pessoas no regime militar brasileiro (1964/1985): estudos de caso", coordenado pelo Prof. Dr. Rogério Gesta Leal. Advogada. 
Resumo: 0 presente ensaio trata da análise das possibilidades de efetivação do acesso à informação em face da nova Lei federal de Acesso às Informações Públicas (Lei 12.527, de 18.11.2012), e com seu Decreto regulamentador (Dec. 7.724, de 16.05.2012). No primeiro momento pretende-se responder se há um Direito Fundamental à Informação e no segundo momento a relação da nova Lei de Acesso à Informação brasileira com a concretização do Direito Fundamental de Acesso à Informação. A partir desses pontos verifica-se que para os fins de apuração da Verdade e Memória dos atos praticados pelo Estado, a restrição de acesso às informações pessoais não pode ser invocada por qualquer argumento, até em respeito ao tratamento que a Lei dá aos Direitos Humanos e Fundamentais, Individuais e Sociais.

Palavras-chave: Direito fundamental à informação - Lei de Acesso à Informação - Regime militar.

\begin{abstract}
This paper deals with the analysis of the possibilities of effective access to information in the face of the new Federal Law on Access to Public Information (12,527, of 18.11.2012) and its regulating Decree (7724, of 16.05.2012). At first we intend to respond if there is a Fundamental Right to Information and the second time the relationship of the new Law on Access to Information Brazilian with the implementation of the Fundamental Right of Access to Information. From these points it appears that for the purposes of ascertaining the Truth and Memory of the acts of the state, restricting access to personal information can not be invoked by any argument, even in regard to the processing that the Human Rights Act gives and fundamental, individual and social.
\end{abstract}

KeYWORDS: Fundamental right to information Access to Information Act - The military regime.

SumÁrio: 1. Elementos introdutórios - 2. Há um direito fundamental à informação - 3. Os novos marcos regulatórios do acesso à informação no Brasil - 4. Considerações finais - 5 . Referências.

\section{ElEMENTOS INTRODUTÓRIOS}

Pretendemos neste ensaio analisar as possibilidades de efetivação do acesso à informação ${ }^{1}$ referente ao tema do acesso à informação em face da nova Lei federal de Acesso às Informações Públicas (Lei 12.527, de 18.11.2011), e com seu Decreto regulamentador (7.724, de 16.05.2012).

O problema é que, eventualmente, as informações relacionadas com o regime militar brasileiro podem revelar o desvelamento de relações sociais, institu-

1. Este texto é fruto das pesquisas que estão sendo desenvolvidas no Grupo de Pesquisa sobre Verdade, memória e justiça: análises da experiência das políticas públicas reparatórias do governo do Rio Grande do Sul envolvendo os atos de sequestro, morte, desaparecimento e tortura de pessoas no regime militar brasileiro (1964/1985), junto ao Programa de Doutorado e Mestrado da Universidade de Santa Cruz do Sul - Unisc, e vinculado ao Diretório de Grupo do CNPQ intitulado Estado, Administração Pública e Sociedade, coordenado pelo Prof. Dr. Rogério Gesta Leal. 
cionais e políticas delicadas, forjadas ao abrigo de impunidades e segredos de Estado até hoje não revelados, seja pela classificação e blindagem de vários documentos, seja pela proteção corporativa de muitos interesses escusos à época - e quiçá até hoje - operantes.

\section{HÁ UM DIREITO FUNDAMENTAL À INFORMAÇÃO}

Já tivemos oportunidade de referir que o tema do acesso à informação enquanto Direito Fundamental não é novo à experiência jurídica do Ocidente ${ }^{2}$ basta ver que a Declaração Universal dos Direitos Humanos, em seu art. 19, trata disto, garantindo que toda pessoa tem direito à liberdade de opinião e expressão; este direito inclui a liberdade de, sem interferência, ter opiniões e de procurar receber e transmitir informações e ideias por quaisquer meios e independentemente de fronteiras. ${ }^{3}$

Da mesma forma na Convenção Americana de Direitos Humanos de 1969, ${ }^{4}$ pode-se encontrar previsão clara no sentido de que toda pessoa tem o direito à liberdade de pensamento e de expressão, e que tal direito inclui a liberdade de procurar, receber e difundir informações e ideias de qualquer natureza, sem considerações de fronteiras, verbalmente ou por escrito, ou em forma impressa ou artística, ou por qualquer meio de sua escolha (art. 13). Ademais, o exercício deste direito não pode estar sujeito à censura prévia, mas a responsabilidades ulteriores, que devem ser expressamente previstas em lei e que se façam necessárias para assegurar tão somente o respeito dos direitos e da reputação das demais pessoas, e a proteção da segurança nacional, da ordem pública, ou da saúde ou da moral públicas.

Como lembra Paula Ligia Martins, a adoção em 1992 da Declaração do Rio sobre Meio Ambiente e Desenvolvimento, já imprimia enorme pressão sobre instituições internacionais para implementar políticas de participação pública e acesso à informação, sendo que o Banco Mundial e quatro bancos regionais de desenvolvimento - Banco Interamericano de Desenvolvimento, Grupo do Banco Africano de Desenvolvimento, Banco Asiático de Desenvolvimento e o

2. Ver livro: Leal, Rogério Gesta. Verdade, memória e justiça no Brasil: responsabilidades compartidas. Porto Alegre: Livraria do Advogado, 2012.

3. Adotada e proclamada pela resolução 217 A (III), da Assembleia Geral das Nações Unidas, em 10.12.1948.

4. Adotada e aberta à assinatura na Conferência Especializada Interamericana sobre Direitos Humanos, em San José de Costa Rica, em 22.11.1969 - ratificada pelo Brasil em 25.09.1992, Diário Oficial da União de 09.11.1992; p. 15562-15567. 
Banco Europeu para Reconstrução e Desenvolvimento - adotaram políticas para liberação de informações. ${ }^{5}$

A Declaração Internacional de Chapultepec, ${ }^{6}$ firmada pelo Presidente Fernando Henrique Cardoso, em 1996, em conjunto com vários presidentes latino-americanos, estabelece em seus Princípios que: Não há pessoas nem sociedades livres sem liberdade de expressão e de imprensa. O exercício desta não é uma concessão das autoridades; é um direito inalienável do povo. Toda pessoa tem o direito de buscar e receber informação, expressar opiniões e divulgá-las livremente. Além disto, refere o documento que as autoridades devem estar legalmente obrigadas a pôr à disposição dos cidadãos, de forma oportuna e equitativa, a informação gerada pelo setor público.

Assim tem se comportado as Constituições de parte significativa dos países Ocidentais, eis que:

"The right of access to official information is now protected by the constitutions of some 60 countries. At least 46, and arguably 53 of these expressly guarantee a 'right' to 'information' or 'documents', or else impose an obligation on the government to make information available to the public. The top courts of six of these countries (Argentina, Canada, France, India, Israel and South Korea) have interpreted the constitution to recognize the right implicitly." 7

5. Martins, Paula Ligia. Acesso à informação: um direito fundamental e instrumental. Revista Acervo, vol. 24, n. 1, p. 236.

6. O documento foi adotado pela Conferência Hemisférica sobre liberdade de Expressão realizada em Chapultepec, na cidade do México, em 11.03.1994. Ele não é um documento de governo, como são os acordos internacionais. Trata-se de uma carta de princípios assinada por Chefes de Estado, juristas e entidades ou cidadãos comuns. O compromisso foi assumido pelo Brasil quando o ex-Presidente Fernando Henrique Cardoso assinou a declaração em 09.08.1996, sendo que o Presidente Luis Inácio Lula da Silva deu continuidade ao trabalho renovando o compromisso no dia 03.05.2006.

7. Disponível em: [http://right2info.org/constitutional-protections-of-the-right-to]. Acesso em: 12.09.2011. Adverte o documento, todavia, que: "Constitutions that guarantee less than general right to government-held information are not included in this count. For instance, we do not include constitutions that guarantee a right only to personal information, or to environmental information, or extend the right only to journalists. Nor do we include in this count constitutions that recognize a 'right to freely seek and receive information' or variations of that phrasing, for instance as part of the right to freedom of expression, unless case-law, actual practice and/or assessments of in-country experts support the conclusion that the right includes a general right to information. We do, however, include in this count a right to government-held information that is limited to information of public interest" (p. 3). 
Especificando mais este mapeamento da forma com que o direito à informação se encontra disposto na ordem constitucional contemporânea, o documento referido dá conta de que:

(a) Em 11 países da América há previsão constitucional sobre tal direito, a saber: Brasil, Chile, Colômbia, Costa Rica, Equador, México, Nicarágua, Panamá, Paraguai, Peru e Venezuela;

(b) Em outros dezessete (17) países há uma clara garantia constitucional deste direito: Albânia, Bulgária, República Checa, Estônia, Finlândia, Grécia, Hungria, Lituânia, Moldova, Noruega, Polônia, Portugal, Romênia, Servia, Slovakia, Slovênia, Suíça;

(c) Igualmente na Ásia e Pacífico pode-se contar com as seguintes constituições tratando da matéria: Nepal, Nova Zelândia, Paquistão, Nova Guiné, Filipinas, Tailândia;

(d) $\mathrm{Na}$ África, têm-se os seguintes países compromissados normativamente com o Direito à Informação: Camarões, República do Congo, Gana, Kênia, Madagascar, Marrocos, Moçambique, Senegal, África do Sul, Tanzânia, Uganda. ${ }^{8}$

Em algumas constituições de países como Azerbaijão, Macedônia, Rússia e Ucrânia, há a explícita garantia do direito de receber informações, mas não especificamente em relação aos órgãos públicos como fornecedores destas, razão pela qual os Tribunais destes países têm progressivamente determinado que tal direito da cidadania também está associado e relacionado aos poderes estatais, devendo estes providenciar as informações postuladas - guardadas as situações impossíveis normativamente de serem publicizadas, como aquelas que envolvem segurança nacional ou perigo de Estado (tema igualmente polêmico na discussão contemporânea da questão) ${ }^{9}$

As constituições do Kênia, Panamá, Polônia, Sérvia e África do Sul, expressamente estendem o Direito à Informação às empresas e ou entidades que exercem funções públicas, bem como às autoridades públicas, garantindo tais constituições o acesso a qualquer informação que é produzida ou está na posse de outra pessoa e é necessária/requerida para o exercício ou proteção de qualquer direito ou liberdade.

8. Idem, p. 4. Alerta o documento ainda que: "Top courts of at least nine of these countries have ruled that the constitutional right is enforceable in court even without enactment of an implementing law, including Chile, Costa Rica, India, Paraguay, the Philippines, South Africa, South Korea, Uganda and Uruguay".

9. Disponível em: [www.ccourt.go.kr/home/english]. Acesso em: 12.09.2011. 
A Inglaterra conta também há bastante tempo com mecanismos de proteção e acesso à informação, registrando um salto desta discussão no período de Tony Blair (1997), inclusive com o chamado Code of Practice on Access to Government Information (Código de Prática sobre Acesso à Informação do Governo), um predecessor não estatutário da legislação específica sobre a matéria, introduzido em 1994. ${ }^{10}$

No final do século XX houve um número crescente de investigações através dos chamados inquéritos públicos - outro instrumento de acesso à informação, destacando-se na experiência inglesa, só a título exemplificativo, o famoso Inquérito Saville, iniciado em 1998, sobre os acontecimentos do chamado Domingo sangrento (quando unidades do Exército britânico mataram pessoas durante uma manifestação pública na Irlanda do Norte). Esse inquérito, que custou aos cofres públicos ingleses milhões de libras, não tendo sido concluído até agora, e resultou em um pedido público de desculpas do governo. ${ }^{11}$

Esta evolução foi tão significativa que durante a década de 1990, os principais serviços secretos da Inglaterra, conhecidos como MI5 (segurança interna) e MI6 (externa e militar), começaram a desenvolver uma face pública de seus documentos, permitindo o acesso às informações sobre atividades passadas e aos seus arquivos, tendo presente que o acesso à informação pode ser negado se: (a) ele se enquadra no fechamento geral, caso, por exemplo, o dossiê forneça informações pessoais ou alegações infundadas contra indivíduos; ou (b) houver uma razão específica para aquele caso, por exemplo, se a polícia estiver considerando dar continuidade às acusações. ${ }^{12}$

Nesta linha de preocupação, a experiência inglesa ainda contou com a edição de um Código de Práticas de Gestão do Acesso à Informação, editado pela

10. Ver maiores informações no site [www.cfoi.org.uk]. Importa destacar que legislação sobre estes temas, de forma mais pontual em relação ao acesso à informação, chamada de FoI, restou introduzida no Reino Unido em 2000, na esteira das leis de proteção de dados de 1984 e 1998, e suplementada pelo Regulamento da Informação Ambiental de 2004 (o qual dá ao público o direito de acesso à informação sobre meio ambiente). A legislação FoI, em suma, dissemina os efeitos e as práticas de abertura dos arquivos correntes do governo central para todas as áreas da administração pública envolvendo todas as operações que não podem ser chamadas estritamente de secretas ou estritamente privadas.

11. Conforme informação no site: [www.bloody-sunday-inquiry.org].

12. Соoк, Michael. Liberdade de Informação: influência da prática profissional em gestão de arquivos. Revista Acervo. vol. 24. n. 1. p. 253. Rio de Janeiro: Arquivo Nacional, jan.-jun. 2011. Ver também o site: [www.mi5.gov.uk]. 
primeira vez em 2002, e com publicação em 2009, numa versão mais completa. O código em si não tem força legislativa, mas constitui um conjunto detalhado de diretrizes para qualquer organização que pretenda estabelecer sistemas práticos de gestão de documentos de acordo com a FoI. ${ }^{13}$

Michael Cook lembra que foi graças à ampliação internacional do acesso à informação que se pôde descobrir, em junho de 2010, as provas definitivas de que o Estado de Israel possuía armas nucleares, eis que, com a implementação das leis de liberdade de informação na África do Sul, conseguiu-se evidências documentais de que Israel ofereceu àquele país, em 1975, a venda de materiais nucleares para armamento, durante o Apartheid. ${ }^{14}$

De outro lado, desde o caso Claude Reyes e outros, contra o Governo Chileno, julgado em 19.09.2006, pela Corte Interamericana de Direitos Humanos, ${ }^{15}$ tem-se uma posição clara no âmbito latino-americano da jurisprudência internacional envolvendo esta matéria, reconhecendo o direito à informação como fundamental, em especial diante do Estado.

Tais posturas vêm alterando a própria compreensão da função institucional e social dos fundos e arquivos públicos, como bem adverte o Prof. Dr. Jaime Antunes:

13. Emitida pelo Ministério da Justiça e pelo National Archives. Lord Chancellor's Code of Practice on the management of records issued under section 46 of the Freedom of Information Act 2000. Disponível em: [www.justice.gov.uk/guidance/docs/Fol-section46-code-of-practice.pdf]. Este código deveria ser lido junto com o Records Management: Data Protection Act 1998: a guide for records managers and archivists. Disponível em: [www.nationalarchives.gov.uk/documents/dpguide.pdf]. Ambos acessados em: jun. 2010.

14. Cook, Michael. Op. cit., p. 248. Cita o autor aqui o trabalho de Polakov-Suransky, Sasha. The unspoken alliance: Israel's secret relationship with apartheid South Africa. New York: Pantheon, 2010.

15. Disponível em: [www.soros.org/initiatives/justice/litigation/chile/d_decision-en_20060919.pdf]. Acesso em: 12.09.2011. Em especial ver também a Open society justice initiative's amicus brief. Disponível em: [www.soros.org/initiatives/justice/litigation/ chile/court-amicus-brief-3282006.pdf.]. Tenha-se presente que a Assembleia Geral da OEA reconhece o direito de acesso à informação como um requisito indispensável para o próprio funcionamento da democracia. Ver a Resolução da Assembleia n. 1.932 (XXXIII-O/03): Acesso à informação pública: fortalecimento da democracia. 10.06.2003. Na mesma direção as resoluções da Assembleia Geral da OEA 2.057 (XXXIVO/04), 2.121 (XXXV-O/05), 2.252 (XXXV-O/06), 2.288 (XXXVII-O/07) e 2.418 (XXXVIII-O/08). Ver também o texto de: Mendel, Toby. Freedom of Information: a comparative legal survey. Paris: United Nations Educational, Scientific, and Cultural Organization, 2008. 
"Com o advento das modernas tecnologias de controle e recuperação da informação, a visão de arquivo como instituição de guarda de documentos foi substituída por aquela que o situa enquanto gestor de um sistema de informação, integrado a outros sistemas, com o objetivo maior de garantir o acesso do usuário às informações demandadas. Ou seja, o eixo foi deslocado da questão da guarda para a do acesso." 16

Nesta linha de raciocínio, resta claro que os documentos e arquivos envolvendo temas de natureza pública - em especial os que dizem com aprendizagens democráticas necessárias - precisam ser manejados para além da conservação meramente histórica, impondo compreensão enquanto fontes de informações que reclamam domínio e debate público emergente, até em face da dicção constitucional do art. 216, § 2. ${ }^{\circ}$, da CF/1988, ao disciplinar que cabe à Administração Pública a gestão da documentação governamental e as providências para franquear sua consulta a quantos dela necessitem.

É interessante a perspectiva de Gentot quando assevera que "freedom of information and data protection are two forms of protection against the Leviathan state that have the aim of restoring the balance between the citizen and the state", ${ }^{17}$ isto porque efetivamente estas duas verdadeiras instituições da Democracia contemporânea por vezes têm rotas de tensionamento muito grandes, aparentando estarem tais Direitos Fundamentais em situação de conflito insuperável entre si.

É notório que os registros do passado e do presente deverão sofrer adequados manejos, avaliações e interpretações, tarefas de tensas conciliações teóricas e práticas, não só pelas distintas escolas e doutrinas que se ocupam disto, mas fundamentalmente em face dos interesses diversos/antagônicos que estão envolvidos, tendo-se dito que a simples existência e posterior organização de documentos desta natureza já implicam a possibilidade tão cara à Democracia de controlar o Poder e seu exercício, notadamente em suas instâncias burocrá-

16. Silva, Jaime Antunes. O centro de referência das lutas políticas no Brasil (1964-1985). Revista Acervo. vol. 21, n. 2, p. 14.

17. Gentot, Michel. Access for information and protection of personal data. Commission Nationale de l'Informatique ET des Libertés. Disponível em: [www.pcpd.org.hk/english/infocentre/files/gentot-paper.doc], p. 12. Acesso em: 02.03.2012. Esclarece o autor que: "Right to information (RTI) laws provide a fundamental right for any person to access information held by government bodies. At the same time, right to privacy laws grant individuals a fundamental right to control the collection of, access to, and use of personal information about them that is held by governments and private bodies". 
ticas, e mais que isto, pode gerar responsabilidades e relações de confiança que formam de maneira crítica a opinião pública da Sociedade Civil. ${ }^{18}$

Em regra, o acesso a documentos pode ser compreendido sob uma perspectiva legal, física, virtual e intelectual, pois envolve o direito e a permissão para usar registros e informações através do acesso a locais físicos e virtuais, atribuindo sentidos múltiplos e possíveis a estes dados, todavia, há ainda muitos obstáculos para tanto, os quais, muitas vezes, têm a ver com questões políticas e de corrupção - além de interesses escusos por trás de tudo isto -, que dificultam o empoderamento social e mesmo a efetividade dos direitos referidos.

Ocorre que as estruturas de poder e as administrativas do seu exercício, mesmo em países com tradições progressivamente democráticas, contam com culturas, ações de governo e sociais, por vezes demasiadamente comprometidas com interesses privados e corporativos pouco transparentes - o que se estende às burocracias estatais e não estatais.

É óbvio que o acesso à informação e dados - seja pela via física, seja pela virtual - é apenas um aspecto dos desafios que se apresentam no tema proposto neste ensaio, isto porque records are complex by nature, because of their origin in complex social processes. Thus, it requires certain skills and knowledge first to locate the relevant records, then to find the relevant item, and finally to interpret and understand the content. ${ }^{19}$

18. Diz, Shapiro, J.; Hughes, S. Information literacy as a liberal art: enlightenment proposals for a new curriculum. Educom Review. Disponível em: [www.educause. edu/pub/er/review/reviewarticles/31231.html]. 1996: "People being aware of their rights and being able to act on them by making use of the public information is an important aspect of the creation of an engaged civil society. Access to information and public records are thus of crucial importance in the reconstruction of a postconflict civil society, and is recognized as a right for citizens in a democratic society in the spirit of the Universal Declaration of Human Rights (art. 19)".

19. Idem, p. 30. É curioso que até na África do Sul tais circunstâncias se fizeram sentir, como lembra Kemoni, Harold, Wamukoya, Norbert; Kiplang'at, Jonh. Obstacles to Utilization of Information Held by Archival Institutions: a Review of Literature. Records Management Journal. 13(1), p. 29, no sentido de que os: "African archives are underutilized as information sources. This is partly due to professional problems like lack of recognition of archives by governments, obsolete legislation, lack of professional training, inadequate service, and inadequate or non-existent access tools. Another impacting factor is lack of appropriate hardware and software and user-friendly systems, lack of knowledge using information technology, costs, and the vulnerability of digital information". 
O âmbito, pois, das questões atinentes ao manejo propriamente dito daquelas informações se revelam importantes até pelo fato de que, em muitos casos, somente elas podem levar ao conhecimento das atrocidades perpetradas para fins de formação da opinião pública, fundamentalmente porque a população que sai de tempos sombrios e ditatoriais possuem sempre algumas expectativas institucionais sobre estas questões. ${ }^{20}$

Considerando tais elementos, pode-se inclusive sustentar que os argumentos relativos à segurança do Estado, defesa nacional ou ordem pública - em muito utilizados para restringir o acesso à informação - devem ser definidos e interpretados em conformidade com o marco jurídico e político do Estado Democrático de Direito e da ordem constitucional vigente, além, é claro, de estar conforme os tratados e convenções protetivos dos Direitos Humanos, em especial a Convenção Americana sobre Direitos Humanos.

$\mathrm{Na}$ base destes argumentos é que o princípio 3, do Conjunto de princípios à proteção e promoção dos Direitos Humanos por meio da luta contra a impunidade, da ONU, estabelece que os Estados têm o dever de recuperar a informação relativa as violações dos direitos humanos de fontes que incluem: (a) órgãos governamentais nacionais, em especial os que tenham desempenhado uma função importante relacionada às violações dos direitos humanos; (b) órgãos locais, tais como delegacias de polícia, que tenham participado de violações dos direitos humanos; (c) órgãos estatais, incluído o gabinete da promotoria e o Poder Judiciário, que participam da proteção dos direitos humanos; e (d) materiais reunidos pelas comissões da verdade ou outros órgãos de investigação. ${ }^{21}$

Com o advento da Constituição brasileira de 1988 restou claro, pelos termos conjugativos do art. 37, caput, e do art. 93, IX e X, que são públicos os atos e negócios da Administração Pública no país, observadas as situações que envolvem segurança nacional ou congênere. Com maior grau de especificidade, pelos termos da Lei federal 9.784, de 29.01.1999, que regula os procedimentos administrativos, de igual sorte restaram consolidados direitos e garantias da cidadania - e da Administração - no atendimento de demandas, inclusive de informação, que se apresentam a esta.

Mas em termos operacionais, o que significa esta transparência administrativa? Junto com a participação nos procedimentos administrativos, à motiva-

20. Ver o texto de Masire, Karl. Democracy and Peace in Africa and the Role of Archives. International Journal on Archives. vol. 32. p. 87. London: Thigger, 2004.

21. In Naciones Unidas. Comisión de Derechos Humanos. Conjunto de principios actualizado para la protección y la promoción de los derechos humanos mediante la lucha contra la impunidad. E/CN.4/2005/102/Add.1. 8.02.2005. Principio 3 ("El deber de recordar"). 
ção e publicidade dos atos administrativos, o darem a conhecer os documentos públicos, perfazem os elementos centrais de conceituação e significado da transparência na espécie.

Agora, em um ordenamento jurídico como o brasileiro, em que vige a exigência da documentação administrativa, o direito de acesso constitui, se não o principal, certamente um dos parâmetros fundamentais para colocar à prova a maturidade do sistema como um todo e verificar a possibilidade de afirmar e concretizar esta centralidade que o cidadão possui no âmbito da gestão do interesse público. Assim, per definizione, accesso si contrappone a segretezza. Il binomio implica un rapporto inversamente proporzionale tra i termini: minore è il grado di segretazione, maggiore è la possibilità di accedere ai documenti. ${ }^{22}$

Por outro lado, a informação e o acesso a ela hoje se afiguram como condição de possibilidade da própria Democracia, da Igualdade e Liberdade, assim como da dignidade da pessoa humana, tanto que, no âmbito do texto constitucional brasileiro vigente podem-se destacar algumas previsões normativas muito claras nesta direção, dentre as quais, no plano formal, tratando de requisitos instrumentais da participação e do controle social da administração pública, as seguintes:

(a) a exigência de publicidade dos atos da Administração, para os fins de garantir um grau de visibilidade do poder político e social, dela não podendo constar nomes, símbolos ou imagens que caracterizem promoção pessoal de autoridades ou servidores públicos,$^{23}$ ao mesmo tempo em que se impõe como requisito de vigência da norma legal; ${ }^{24}$

(b) o direito do cidadão em obter certidões do Poder Público, visando trazer informações oficiais sobre interesses pessoais e determinados, consoante disposição constitucional inscrita no art. . $^{\circ}$, XXXIV, do mesmo Estatuto;

22. Arena, Gregório. Il Segreto Amministrativo. Padova: Cedam, 2004, p. 34. Refere ainda o autor que: "l'accesso ai documenti amministrativi, attese le sue rilevanti finalità di pubblico interesse, costituisce principio generale dell'attività amministrativa al fine di favorire la partecipazione e di assicurarne l'imparzialità e la trasparenza".

23. Nos termos do art. 37, caput e $\S 1 .^{\circ}$, da CF/1988, destacando-se este publicidade como princípio informativo da própria Administração Pública.

24. Cumpre destacar que a publicidade, neste particular, não é elemento formativo do ato, necessário a existência válida deste ato, salvo quando a lei o dispuser, mas será sempre requisito de sua eficácia, exeqüibilidade e de sua moralidade. Neste sentido, ver o texto de: Moreira Neto, Diogo de Figueiredo. Direito de participação política. Rio de Janeiro: Renovar, 1993. p. 107 e ss. 
(c) o direito de petição, garantido a qualquer pessoa, independentemente de ser ou não cidadão, alcançando aos três poderes do Estado, para os fins de defesa de direitos ou contra ilegalidade ou abuso de poder, nos termos do art. 5. ${ }^{\circ}, \mathrm{XXXIV}, a$.

Estes temas estão igualmente relacionados à questão da boa governança, $\mathrm{e}$ dos chamados governos abertos, que devem informar os cidadãos sobre os seus direitos e promover uma cultura de abertura no seio do governo, única forma de ampliar os níveis de legitimidade das decisões políticas. ${ }^{25}$

Veja-se que no plano da infraconstitucionalidade, o Brasil já contava com o Dec. 79.099, de 06.01.1977, posteriormente revogado pela Lei federal 8.159, de 08.01.1991, e sua regulamentação pelo Dec. 21.134, de 02.01.1997 (o qual foi revogado pelo Dec. 4.553, de 27.12.2002 e suas alterações - em especial a do Dec. 5.301, de 09.12.2004), editado em pleno regime militar, pelo então Presidente General Ernesto Geisel, e que lançou os marcos conceituais preliminares sobre a matéria que os demais institutos jurídicos basicamente repetiram, chegando as minúcias de definir categorias próprias de blindagem e segredo documental. ${ }^{26}$

Em 05.05.2005, ainda se teve a Lei federal 11.111, recentemente substituída pela Lei federal 12.527, de 18.11.2011, que estabelece novos parâmetros para o tratamento destas questões, e seu Decreto regulamentador 7.724, de 16.05.2012, tema que passo a abordar.

\section{OS NOVOS MARCOS REGULATÓRIOS DO ACESSO À INFORMAÇÃO NO BRASIL}

A nova Lei de Acesso à Informação brasileira referida, em seu art. 3. ${ }^{\circ}$, já de pronto estabelece que seus procedimentos devem vir ao encontro da concretização do que chama de direito fundamental de acesso à informação, observados os princípios básicos da administração pública e as seguintes diretrizes: (a) observância da publicidade como preceito geral e do sigilo como exceção; (b) divulgação de informações de interesse público, independentemente de soli-

25. Autor Rogério tratou deste tema no livro: LeAl, Rogério Gesta. Estado, Administração Pública e sociedade: novos paradigmas. Porto Alegre: Livraria do Advogado, 2006, assim como no livro: Leal, Rogério Gesta (org.). A democracia deliberativa como nova matriz de gestão pública: estudo de casos. Santa Cruz do Sul: Edunisc, 2011 - e-book, localizado no site: [www.unisc.br].

26. O autor Rogério aborda de forma mais aprofundada este tema em seu livro: LEAL, Rogério Gesta. Verdade, memória e justiça no Brasil... cit. Ver o texto de Cook, Michael. Op. cit., p. 245 e ss. 
citações; (c) utilização de meios de comunicação viabilizados pela tecnologia da informação; (d) fomento ao desenvolvimento da cultura de transparência na administração pública; (e) desenvolvimento do controle social da administração pública.

Por certo que tais diretrizes se apresentam de forma vinculante para o Estado, e implicam, em nome da coerência teleológica da norma, a adoção de políticas públicas específicas que vão dar densidade material e eficacial aos enunciados sob comento. Significa dizer que, da leitura integrada de todas estas diretrizes, compete ao Poder Público gerar medidas e ferramentas de revisão de todos os seus acervos e fundos que ainda não contam com acesso irrestrito, exatamente para se afastar o máximo possível do segredo de dados e informações que possui, dando a saber à população sobre o que lhe pode ser útil para o exercício pleno da cidadania - mediante procedimentos objetivos, ágeis, claros e em linguagem de fácil compreensão (art. 5. ${ }^{\circ}$ da Lei 12.527/2011) -, valendo-se inclusive, para tanto, dos recursos das tecnologias virtuais, ampliando os níveis de transparência e controle social. ${ }^{27}$

De forma mais precisa, a novel legislação, em seu art. $7 .^{\circ}$, houve por bem demarcar no que consiste, exemplificativamente, aquele Direito Fundamental à Informação: (a) obter orientação sobre os procedimentos para a consecução de acesso, bem como sobre o local onde poderá ser encontrada ou obtida a informação almejada; (b) obter informação contida em registros ou documentos, produzidos ou acumulados por seus órgãos ou entidades, recolhidos ou não a arquivos públicos; (c) obter informação produzida ou custodiada por pessoa física ou entidade privada decorrente de qualquer vínculo com seus órgãos ou entidades, mesmo que esse vínculo já tenha cessado; (d) obter informação sobre atividades exercidas pelos órgãos e entidades, inclusive as relativas à sua política, organização e serviços. ${ }^{28}$

27. É disposição expressa do art. 8. ${ }^{\circ}$ da Lei 12.527/2011 que é dever dos órgãos e entidades públicas promover, independentemente de requerimentos, a divulgação em local de fácil acesso, no âmbito de suas competências, de informações de interesse coletivo ou geral por eles produzidas ou custodiadas. Já no $\S 2 .^{\circ}$, do art. 10 , restou disposto que os órgãos e entidades do Poder Público devem viabilizar alternativa de encaminhamento de pedidos de acesso a informações por meio de seus sítios oficiais na Internet.

28. Excluídas as informações referentes a projetos de pesquisa e desenvolvimento científicos ou tecnológicos cujo sigilo seja imprescindível à segurança da sociedade e do Estado $\left(\S 1 .^{\circ}\right.$, art. $\left.7 .^{\circ}\right)$, sendo que quando não for autorizado acesso integral à informação por ser ela parcialmente sigilosa, é assegurado o acesso à parte não sigilosa por meio de certidão, extrato ou cópia com ocultação da parte sob sigilo $\left(\S 2 .^{\circ}\right)$. Por outro 
Em face deste Direito Fundamental, qualquer interessado poderá apresentar pedido de acesso a informações aos órgãos e entidades referidos na Lei, por qualquer meio legítimo, devendo o pedido conter a identificação do requerente e a especificação da informação requerida, sendo que para o acesso a informações de interesse público, a identificação do requerente não pode conter exigências que inviabilizem a solicitação (art. 10, § 1. ${ }^{\circ}$, da Lei 12.527/2011).

O que é mais importante: são vedadas quaisquer exigências relativas aos motivos determinantes da solicitação de informações de interesse público art. 10, § $3^{\circ}$, da Lei 12.527/2011 (e art. 14 do Dec. 7.724/2012), medida absolutamente necessária para que se atinjam os fins almejados pela normativa, principalmente quando os dados que se quer buscar dizem com interesses conflitantes e delicados sob o ponto de vista político e histórico.

Todavia, consta de forma clara no art. 13, do Decreto regulamentador (Dec. 7.724/2012), que:

"Art. 13. Não serão atendidos pedidos de acesso à informação:

I - genéricos;

II - desproporcionais ou desarrazoados; ou

III - que exijam trabalhos adicionais de análise, interpretação ou consolidação de dados e informações, ou serviço de produção ou tratamento de dados que não seja de competência do órgão ou entidade."

Poder-se-ia perguntar se os juízos de valor sobre o que são pedidos genéricos, desproporcionais e desarrazoados, ou mesmo que exijam trabalhos adicionais de análise, interpretação ou consolidação de dados e informações, ficam ao alvedrio da subjetividade da autoridade pública a quem é dirigida a postulação! E mais, se para tais deliberações não se imporia, para diminuir os níveis de discricionariedade administrativa, a demarcação de parâmetros mais objetivos de restrição ao acesso?

De qualquer sorte, negado o pedido de acesso à informação, será enviada ao requerente, no prazo de resposta, comunicação oficial contendo os seguintes elementos: as razões da negativa de acesso e seu fundamento legal; a possibilidade e prazo de recurso, com indicação da autoridade que o apreciará; e a possibilidade de apresentação de pedido de desclassificação da informação,

lado, a negativa de acesso às informações objeto de pedido formulado aos órgãos e entidades referidas no art. $1 .^{\circ}$, quando não fundamentada, sujeitará o responsável a medidas disciplinares, nos termos do art. 32 da Lei 12.527/2011 (§ $\left.2 .^{\circ}\right)$. 
quando for o caso, com indicação da autoridade classificadora que o apreciará (art. 19 do Dec. 7.724/2012). ${ }^{29}$

No ponto que interessa a este trabalho, dispõem os arts. 21 e 22, da Lei 12.527/2011 que:

"Art. 21. Não poderá ser negado acesso à informação necessária à tutela judicial ou administrativa de direitos fundamentais.

Parágrafo único. As informações ou documentos que versem sobre condutas que impliquem violação dos direitos humanos praticada por agentes públicos ou a mando de autoridades públicas não poderão ser objeto de restrição de acesso.

Art. 22. O disposto nesta Lei não exclui as demais hipóteses legais de sigilo e de segredo de justiça nem as hipóteses de segredo industrial decorrentes da exploração direta de atividade econômica pelo Estado ou por pessoa física ou entidade privada que tenha qualquer vínculo com o Poder Público."

Podem-se celebrar tais dispositivos porque ratificam o princípio da publicidade que informa o acesso a dados e informações em mãos do Poder Público, todavia há que se perquirir sobre o alcance da norma para tão somente os casos em que tais documentos estejam vinculados à tutela judicial ou administrativa de Direitos Fundamentais, ou seja, o acesso pode ser negado se não forem estas as situações? Quando se pretenda tão somente conhecer o que consta em tais documentos para fins de esclarecimento público, isto pode ser compreendido como Direito Fundamental Social Difuso? A meu juízo sim, pois o art. 21 da Lei 12.527/2011 não discrimina espécies de Direitos Fundamentais - e nem poderia, e por isto engloba tanto Direitos Fundamentais Individuais como Sociais, até em face da leitura integrada que se deve fazer desta norma com o disposto no art. 3. ${ }^{\circ}$, da Lei 12.527/2011.

Andou bem o legislador ao deixar explícito no parágrafo único, do art. 21, que "as informações ou documentos que versem sobre condutas que impliquem violação dos direitos humanos praticada por agentes públicos ou a mando de autoridades públicas não poderão ser objeto de restrição de acesso", pois isto diz com as ações do Estado, através de seus agentes de segurança pública,

29. Demanda a norma que as razões de negativa de acesso à informação classificada indicarão o fundamento legal da classificação, a autoridade que a classificou e o código de indexação do documento classificado - $\$ 1 .^{\circ}$, do art. 19. O problema é que a legislação regulamentadora criou número excessivo de recursos (cinco), nos termos dos arts. 21 a 24 do Dec. 7.724/2012, burocratizando demasiadamente o procedimento. 
que operaram sequestros, mortes, torturas e desaparecimento de pessoas durante o regime militar no país. ${ }^{30}$

É óbvio que para se ter um juízo de valor sobre se aqueles documentos e informações se prestam à tutela de Direitos e se versam sobre condutas violadoras destes mesmos Direitos (e se foram praticados por agentes públicos ou a mando de autoridades públicas), será preciso análise preliminar e percuciente, atividade esta que não poderá se restringir aos juízos de valor, por exemplo, de uma Comissão Mista de Reavaliação de Informações (art. 35 da Lei 12.527/2011), órgão da própria Administração Pública que deve garantir o acesso, sob pena de incoerência total da Lei. Mas é pertinente o questionamento, principalmente quando tais demandas se derem em face dos documentos classificados como ultrassecretos, secretos e reservados (até por decorrência do que dispõe o art. 22, no sentido de que "o disposto nesta Lei não exclui as demais hipóteses legais de sigilo e de segredo de justiça"), quem terá legitimidade e competência para deliberar sobre a acessibilidade perquirida? Com base em que critérios e argumentos?

No mínimo, a meu sentir, a deliberação sobre esta matéria deverá ser compartida entre as partes interessadas, observado o devido processo legal (administrativo ou judicial), notadamente havendo discordância de compreensão, conceituação e interesses entre elas.

Por tais argumentos é que o segredo de Estado não tem vez nos regimes democráticos contemporâneos, sendo até possível, em raríssimas e muito bem

30. Veja-se que o art. 32 da Lei 12.527/2011, é muito claro em determinar que constituem condutas ilícitas que ensejam responsabilidade do agente público ou militar: "I - recusar-se a fornecer informação requerida nos termos desta Lei, retardar deliberadamente o seu fornecimento ou fornecê-la intencionalmente de forma incorreta, incompleta ou imprecisa; II - utilizar indevidamente, bem como subtrair, destruir, inutilizar, desfigurar, alterar ou ocultar, total ou parcialmente, informação que se encontre sob sua guarda ou a que tenha acesso ou conhecimento em razão do exercício das atribuições de cargo, emprego ou função pública; III - agir com dolo ou má-fé na análise das solicitações de acesso à informação; IV - divulgar ou permitir a divulgação ou acessar ou permitir acesso indevido à informação sigilosa ou informação pessoal; V - impor sigilo à informação para obter proveito pessoal ou de terceiro, ou para fins de ocultação de ato ilegal cometido por si ou por outrem; VI - ocultar da revisão de autoridade superior competente informação sigilosa para beneficiar a si ou a outrem, ou em prejuízo de terceiros; e VII destruir ou subtrair, por qualquer meio, documentos concernentes a possíveis violações de direitos humanos por parte de agentes do Estado". E mais: "O disposto neste artigo aplica-se à pessoa física ou entidade privada que, em virtude de vínculo de qualquer natureza com órgãos ou entidades, tenha acesso à informação sigilosa ou pessoal e a submeta a tratamento indevido" (parágrafo único). Lembrando ainda que o art. $11 \mathrm{da}$ Lei de Improbidade Administrativa (Lei 8.429/1992), enumera como ímprobo (dentre outras) a ação do funcionário público que negar publicidade aos atos oficiais - inc. IV. 
justificadas situações, aceitar-se a existência da informação e do documento secreto, porém, não mais reportado à posição do seu detentor ou produtor, mas à qualidade da informação envolvida e o que protege, superando-se, desta maneira, o fundamento meramente subjetivo e pessoal do segredo administrativo - um documento é segredo porque pertence à Administração Pública, ou porque o Administrador assim o entende -; mas pelo fato de representar concessão objetiva e real (tal documento/informação é segredo em face da qualidade da informação que contém, justificado normativa e racionalmente).

Pode-se imaginar, no ponto, a situação do art. 5. ${ }^{\circ}$, XXXIII, da CF/1988, ao disciplinar que todos têm direito a receber dos órgãos públicos informações de seu interesse particular, ou de interesse coletivo ou geral, que serão prestadas no prazo da lei, sob pena de responsabilidade, ressalvadas aquelas cujo sigilo seja imprescindível à segurança da sociedade e do Estado. ${ }^{31}$

Mas, afinal, quais são as informações cujo sigilo seja imprescindível à segurança da Sociedade e do Estado? Quem define, e como o faz, os critérios de eleição desta imprescindibilidade? De que tipo de segurança se está falando aqui em face da Sociedade e do Estado?

A nova Lei de Acesso às informações públicas sob comento, em seu art. 23 da Lei 12.527/2011, delimita quais as informações que se apresentam imprescindíveis à segurança da sociedade ou do Estado e, portanto, passíveis de classificação restritiva de acesso, a saber:

"Art. 23. São consideradas imprescindíveis à segurança da sociedade ou do Estado e, portanto, passíveis de classificação as informações cuja divulgação ou acesso irrestrito possam:

I - pôr em risco a defesa e a soberania nacionais ou a integridade do território nacional;

II - prejudicar ou pôr em risco a condução de negociações ou as relações internacionais do País, ou as que tenham sido fornecidas em caráter sigiloso por outros Estados e organismos internacionais;

III - pôr em risco a vida, a segurança ou a saúde da população;

IV - oferecer elevado risco à estabilidade financeira, econômica ou monetária do País;

31. Alia-se a isto o disposto no art. $37, \S 3 .^{\circ}$, da CF/1988, ao dispor que a lei disciplinará as formas de participação do usuário na administração pública direta e indireta, regulando especialmente: "II - o acesso dos usuários a registros administrativos e a informações sobre atos de governo; mais o art. 216, § 2..$^{\circ}$, estabelecendo que cabe à Administração Pública, na forma da lei, a gestão da documentação governamental e as providências para franquear sua consulta a quantos dela necessitem". 
V - prejudicar ou causar risco a planos ou operações estratégicos das Forças Armadas;

VI - prejudicar ou causar risco a projetos de pesquisa e desenvolvimento científico ou tecnológico, assim como a sistemas, bens, instalações ou áreas de interesse estratégico nacional;

VII - pôr em risco a segurança de instituições ou de altas autoridades nacionais ou estrangeiras e seus familiares; ou

VIII - comprometer atividades de inteligência, bem como de investigação ou fiscalização em andamento, relacionadas com a prevenção ou repressão de infrações." 32

Talvez uma hipótese deste dispositivo pudesse alcançar agentes públicos envolvidos em atos violatórios de Direitos Fundamentais no período da repressão: "quando as informações a este título puserem em risco a segurança de instituições ou de altas autoridades nacionais ou estrangeiras e seus familiares" (inc. VII), isto porque eventuais divulgações de dados sobre estas pessoas poderiam gerar reações mais incisivas de protesto e denúncias contra o ocorrido - revanchismo vingança etc., como o que ocorreu em Porto Alegre e em outras Capitais brasileiras recentemente - mas, diga-se de pronto, sem qualquer incidente de violência:

Manifestantes protestam em frente à casa do ex-chefe do SNI em Porto Alegre

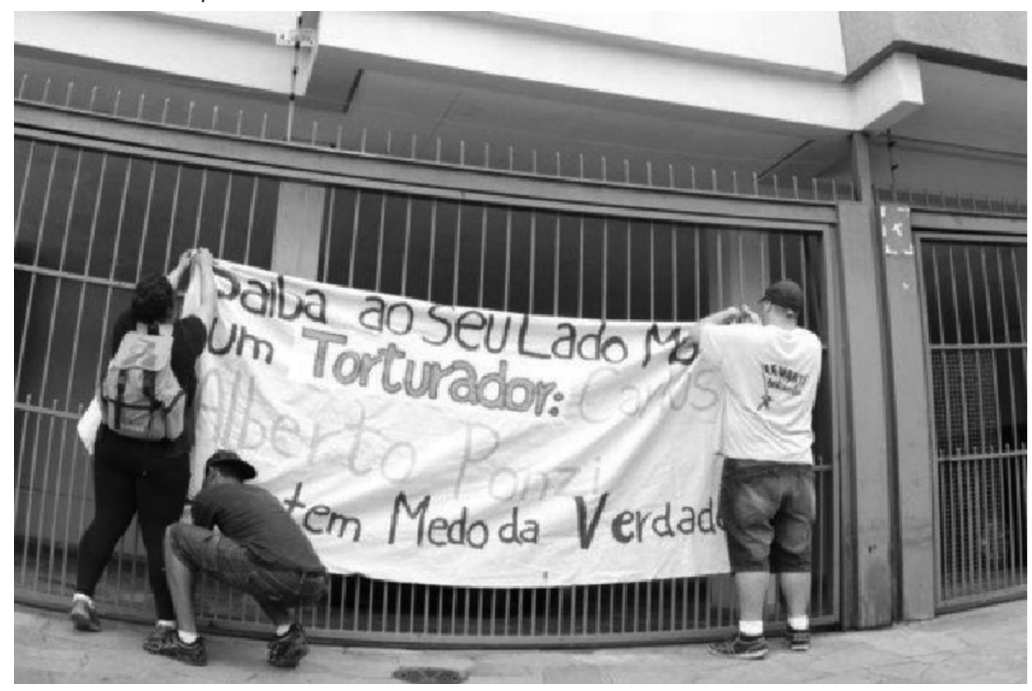

Jovens colocaram faixa em frente ao prédio do ex-chefe do SNI. Foto: Leandro Silva.

32. As mesmas disposições estão no art. 25 e seus incisos do Decreto regulamentador. 
"Jovens integrantes do Levante Popular da Juventude protestaram na manhã desta segunda-feira em frente à casa do coronel Carlos Alberto Ponzi, ex-chefe do Serviço Nacional de Informações de Porto Alegre. O ato integrou uma manifestação nacional para expor publicamente ex-militares e policiais acusados de tortura, abusos sexuais e homicídios durante a ditadura militar (1964-1985).

Os atos ocorreram em frente à casa ou no local de trabalho dos acusados. Além do Rio Grande do Sul, ocorreram ações em São Paulo, Minas Gerais, Santa Catarina, Pará e Ceará.

De acordo com Rafael Coelho, estudante e integrante do Levante Popular em Porto Alegre, as manifestações ocorrem em defesa da criação da Comissão da Verdade - incumbida de investigar e documentar as violações de direitos humanos ocorridas no Brasil entre 1946 e 1988.

- Identificamos os locais de trabalho dos acusados e onde eles moram para denunciar à sociedade que eles continuam vivos e impunes - afirmou Coelho.

O Coronel Carlos Alberto Ponzi é um dos 13 brasileiros acusados pela Justiça italiana pelo desaparecimento do militante político Lorenzo Ismael Viñas em Uruguaina (RS), no ano de 1980. Os cerca de 100 manifestantes colocaram faixas em frente ao prédio onde ele mora, na capital gaúcha, e picharam na calçada as frases "Aqui mora um torturador" e "Carlos Alberto Ponzi, torturador".

Em São Paulo, o alvo dos protestos foi a sede da empresa de segurança privada Dacala, do delegado aposentado do antigo Departamento de Ordem Política e Social (Dops), David dos Santos Araujo. Cerca de 200 pessoas - com cartazes que traziam estampados os rostos de presos políticos mortos durante a ditadura - denunciaram a participação do ex-delegado em assassinatos e tortura durante o regime.

O ex-delegado Santos Araujo é acusado pelo Ministério Público Federal (MPF) de participar da tortura e do assassinato, em abril de 1971, do ativista político Joaquim Alencar de Seixas. De acordo com o MPF, o ex-delegado foi reconhecido por parentes da vítima. Em 30.08.2010, o MPF moveu ação pública para que Araujo fosse pessoalmente responsabilizado pelas práticas criminosas.

Segundo o relato do atual presidente do Conselho Estadual de Defesa da Pessoa Humana de São Paulo, Ivan Seixas, preso aos 16 anos, junto com o pai, Joaquim Alencar de Seixas, David dos Santos Araujo, o 'capitão Lisboa', estava entre os torturadores." 33

33. Disponível em: [http://zerohora.clicrbs.com.br/rs/noticia/2012/03/manifestantes-protestam-em-frente-a-casa-do-ex-chefe-do-sni-em-porto-alegre-3706932.html], matéria veiculada e acessada em: 27.03.2012. 
Citamos esta notícia jornalística exatamente para tencionar a discussão em torno do que se pode admitir como razoável e suportável em termos de manifestação individual e social ordeira de veiculação do pensamento e da opinião, esta sim imperativo categórico das democracias contemporâneas, o que não configuraria em hipótese alguma ameaça à vida, segurança e saúde de quem quer que seja. Ao revés, impõem o dever de suportar a todos que com tal comportamento não concordam. ${ }^{34}$

Ou seja, é necessário que se tenham evidências muito verossímeis do estado de perigo real aos bens e patrimônios referidos para que se viabilizem medidas restritivas de direitos e, no caso, do acesso a informações.

O problema que se teria ainda neste inc. VII do art. 23 da Lei 12.527/2011 é o de saber quem se enquadra na definição de altas autoridades nacionais ou estrangeiras e seus familiares? Quais os requisitos objetivos para definir quem é alta autoridade para os efeitos desta disposição normativa? Apenas alguém que detenha a mais alta patente oficial de nível hierárquico em alguma corporação - pública ou privada?

De qualquer sorte, com base no princípio da publicidade e do acesso irrestrito nos casos de tutela de Direitos Fundamentais, e ainda nos parâmetros de classificação de documentos impostos pelo § 5. ${ }^{\circ}$ do art. 24 da Lei 12.527/2011 ("para a classificação da informação em determinado grau de sigilo, deverá ser observado o interesse público da informação e utilizado o critério menos restritivo possível, considerados: I - a gravidade do risco ou dano à segurança da sociedade e do Estado; e II - o prazo máximo de restrição de acesso ou o evento que defina seu termo final"), nenhuma das hipóteses analisadas teriam o condão de impedir o manejo dos dados e informações pertinentes para estes casos. ${ }^{35}$

34. Na experiência norte-americana, há um precedente muito interessante na Suprema Corte no caso Landmark Communications, Inc., appellant, vs. Commonwealth of Virginia. 435 U.S. 829 (98 S.Ct. 1535, 56 L.Ed.2d 1), julgado em maio de 1978, que exatamente trata da questão que envolve a possibilidade de discussão sobre assuntos governamentais - em face da Primeira Emenda -, e diz que a restrição deste direito demanda que: "The mere fact that the legislature found a clear and present danger to the orderly administration of justice justifying enactment of the challenged statute did not preclude the necessity of proof that such danger existed. This Court has consistently rejected the argument that out-of-court comments on pending cases or grand jury investigations constituted a clear and present danger to the administration of justice". See Bridges vs. California, 314 U.S. 252, 62 S.Ct. 190, 86 L.Ed. 192; Pennekamp vs. Florida, 328 U.S. 331, 66 S.Ct. 1029, 90 L.Ed. 1295; Craig vs. Harney, 331 U.S. 367, 67 S.Ct. 1249, 91 L.Ed. 1546; Wood v. Georgia, 370 U.S. 375, 82 S.Ct. 1364, 8 L.Ed.2d 569.

35. O art. 27 do Dec. 7.724/2012, trata do mesmo tema. 
Por outro lado, não se pode esquecer a experiência internacional neste ponto, no sentido de sustentar que a recusa na divulgação da informação só poderá ser justificada se a autoridade pública puder demonstrar que, naquele caso concreto, tal limitação atende ao chamado teste de três fases, elaborado pela jurisprudência internacional.

"O teste de três fases tem por objetivo avaliar, em cada caso concreto, a relação custo (dano) e benefício (interesse público) na divulgação de uma dada informação. Segundo o teste de três fases, a determinação da confidencialidade em um dado caso concreto só pode ser considerada legítima se presentes os seguintes requisitos: a informação solicitada relaciona-se a um dos objetivos legítimos para restrição do acesso à informação, listados em lei; a divulgação daquela informação específica poderá efetivamente causar graves danos a tal objetivo; e o prejuízo ao objetivo em questão deve ser maior do que o interesse público na liberação da informação específica."36

A pergunta aqui é se aqueles critérios servirão à desclassificação documental? A resposta é afirmativa, eis que o art. 35 do Decreto regulamentador, dispôs que a classificação das informações será reavaliada pela autoridade classificadora ou por autoridade hierarquicamente superior, mediante provocação ou de ofício, para desclassificação ou redução do prazo de sigilo, sendo que, para tanto, dever-se-á observar o cumprimento do disposto no art. 27, ou seja, observando-se o interesse público da informação e utilizando o critério menos restritivo possível, considerados tanto a gravidade do risco ou dano à segurança da sociedade e do Estado, como o prazo máximo de classificação em grau de sigilo ou o evento que defina seu termo final.

Ainda demanda este art. 35 do Dec. 7.724/2012 que deverá ser observado na desclassificação: o prazo máximo de restrição de acesso à informação, previsto no art. 28 , e o prazo máximo de quatro anos para revisão de ofício das informações classificadas no grau ultrassecreto ou secreto, previsto no inc. I do caput do art. 47; a permanência das razões da classificação, a possibilidade de danos ou riscos decorrentes da divulgação ou acesso irrestrito da informação; e a peculiaridade das informações produzidas no exterior por autoridades ou agentes públicos, sendo que "o pedido de desclassificação ou de reavaliação da classificação poderá ser apresentado aos órgãos e entidades independente de existir prévio pedido de acesso à informação" - art. 36.

36. Martins, Paula Ligia. Op. cit., p. 238. Há um conjunto de princípios informativos do acesso à informação que vem sendo debatidos pelo site "Article 19" [http://artigol9. org/], onde se percebe a importância da regulamentação voltada à abertura e transparência destes temas. 
Mas quem fará as avaliações da existência de condições ou não à desclassificação? Aqui está um problema!

Diz o Decreto regulamentador sob comento, em seu art. 34, que:

"Art. 34. Os órgãos e entidades poderão constituir Comissão Permanente de Avaliação de Documentos Sigilosos - Cpads, com as seguintes atribuições:

I - opinar sobre a informação produzida no âmbito de sua atuação para fins de classificação em qualquer grau de sigilo;

II - assessorar a autoridade classificadora ou a autoridade hierarquicamente superior quanto à desclassificação, reclassificação ou reavaliação de informação classificada em qualquer grau de sigilo;

III - propor o destino final das informações desclassificadas, indicando os documentos para guarda permanente, observado o disposto na Lei 8.159, de 08.01.1991; e

IV - subsidiar a elaboração do rol anual de informações desclassificadas e documentos classificados em cada grau de sigilo, a ser disponibilizado na Internet." ${ }^{\text {37 }}$

Como se pode permitir tamanha liberalidade e poder à decisão de classificação e desclassificação de documentos no país? Não seria muito mais democrático e legítimo a determinação de que se constituíssem nas instituições detentoras e produtoras de documentos sigilosos Comissões Permanentes de Avaliação de Documentos Sigilosos, exatamente para diminuir os níveis de subjetividade desta deliberação, tomada por agentes públicos de ocasião que estejam respondendo eventualmente por algum setor, órgão ou departamento - secretarias, ministérios? ${ }^{38}$

Inexistindo tais Comissões, é certo que a classificação e desclassificação documental deverá ser fundamentada e publicizada - por exigência normativa, mas com alto grau de decisionismo institucional monocrático e não colegiado, com debilidade dos espaços de controle preventivo, a despeito que o decurso de prazo opera a liberalização do acesso de documentos classificados.

O Arquivo Nacional do Brasil já tomou providências responsáveis sobre o tema, ao editar a Portaria 59, de 17.05.2012, instituindo sua Comissão de Análise de Documentos com Informações Pessoais, exatamente para aferir colegiadamente as pretensões de acesso a documentos que eventualmente estejam colidindo com direitos individuais.

37. Grifo nosso.

38. Estamos nos referindo à autoridade máxima de cada órgão, conforme definição do art. 45 do Decreto regulamentador. 
Na mesma data, através do edital n. 01, o Arquivo Nacional demarcou os conjuntos documentais relacionados, direta ou indiretamente, ao Sistema Nacional de Informações e Contrainformação - SISNI, sob sua custódia, que se afiguram como necessários à recuperação de fatos históricos de maior relevância nos termos do $\S 4 .^{\circ}$ do art. 31 da Lei 12.527/2012, e do inc. II do art. 58 do Dec. 7.724/2012, que regulamenta a Lei de Acesso a Informações. E o fez para proporcionar que os titulares das informações pessoais contidas nos conjuntos documentais referidos possam apresentar, com base no inc. X do art. $5 .^{\circ}$ da CF/1988, e nos incs. I e II do $\S 1 .^{\circ}$ do art. 31 da Lei 12.527/2011, no prazo de 30 dias corridos, contados da data de publicação do edital, requerimento de manutenção da restrição de acesso aos documentos sobre sua pessoa, sob pena de, no trigésimo primeiro dia, serem tais documentos franqueados de forma irrestrita.

Por fim, é o art. 31 da Lei de Acesso, que trata das informações pessoais sob a guarda/custódia e gestão do Poder Público ou em seu nome, e neste sentido refere que elas devem ser tratadas de forma transparente e com respeito à intimidade, vida privada, honra e imagem das pessoas, bem como às liberdades e garantias individuais, sendo que receberam restrição de acesso (somente aos agentes públicos legalmente autorizados e à pessoa a que elas se referem), independente de classificação, pelo prazo máximo de 100 anos, a contar da data de sua produção (art. 31, \& 1. ${ }^{\circ}$, I, da Lei 12.527/2011).

Ressalva o dispositivo, todavia, que o consentimento para o acesso da pessoa a que se referem às informações e dados não será necessário quando se voltarem para os fins de: (a) prevenção e diagnóstico médico, quando a pessoa estiver física ou legalmente incapaz, e para utilização única e exclusivamente para o tratamento médico; (b) realização de estatísticas e pesquisas científicas de evidente interesse público ou geral, previstos em lei, sendo vedada a identificação da pessoa a que as informações se referirem; (c) cumprimento de ordem judicial; (d) defesa de direitos humanos; ou (e) proteção do interesse público e geral preponderante. (§ 3. ${ }^{\circ}$ ); e mais:

"§ 4. ${ }^{\circ}$ A restrição de acesso à informação relativa à vida privada, honra e imagem de pessoa não poderá ser invocada com o intuito de prejudicar processo de apuração de irregularidades em que o titular das informações estiver envolvido, bem como em ações voltadas para a recuperação de fatos históricos de maior relevância."

Ainda é de se lembrar a interessante distinção que faz Sergio Carrara sobre o que sejam informações pessoais e informação pessoal privada, pois frequentemente parece haver um deslizamento irrefletido de um termo para o outro. Talvez isso se explique por serem as informações pessoais privadas as que colocam de 
modo mais agudo os dilemas éticos que envolvem a relação entre os cidadãos e o Estado e entre os pesquisadores e suas fontes. ${ }^{39}$

Tem-se que ter presente, no particular, o que diz o art. 41 do Decreto regulamentador da Lei de Acesso, que as informações sobre condutas que impliquem violação dos Direitos Humanos praticadas por agentes públicos ou a mando de autoridades públicas (segmentos da sociedade civil que colaboram com o regime de exceção) não poderão ser objeto de classificação em qualquer grau de sigilo nem ter seu acesso negado - mesmo aquelas que revelem, por exemplo, que determinada pessoa teve um amante, era homossexual, entregou um companheiro na tortura ou sofreu indignações nos interrogatórios que não devem ser reveladas.

Isto é importante porque, como lembra James Green, há ainda alguns diretores de arquivos que limitam pesquisas apenas aos documentos genéricos de uma determinada organização considerada subversiva, sem permitir o acesso a qualquer material sobre um indivíduo, sem a sua autorização, ou, no caso da pessoa já ter morrido, apenas com a autorização do parente mais próximo. ${ }^{40}$ Mas como refere o autor:

"É só à luz do dia, na revelação dessas arbitrariedades, que poderemos enfrentar e eliminar essa mancha autoritária na história brasileira. Esconder os excessos do regime, não permitir que os historiadores ou o cidadão tenham acesso à documentação pública, produzida pelo Estado, é manter o silêncio e preservar o poder arbitrário do Estado (....)

Como argumentei no começo do artigo, é raro o documento que não contém uma mentira, distorção, falsificação ou silêncio. Essas mentiras são culpa e responsabilidade das forças de repressão e não do arquivo do estado que guarda a documentação. Se alguém quer processar outro alguém por ter publicado

39. Carrara, Sergio. Do direito de saber: o acesso à informação pessoal privada nos arquivos da ditadura militar brasileira. Revista Acervo, vol. 24, n. 1, p. 197. Lembra o autor no texto que: "Informações pessoais podem ser públicas, como as contidas em um currículo ou em uma ficha criminal; ou privadas, como as relativas à vida bancária ou sexual. Podem ainda habitar um espaço social pouco definido, em que sua 'natureza' está em discussão; ou seja, onde se contesta se devem ser consideradas públicas ou privadas. Como exemplos, poderíamos pensar na vida tributária ou em certos aspectos da vida sexual. Em relação a esse último tipo de informação, lembro que atualmente há vozes em defesa da inclusão de pergunta sobre a orientação sexual nos censos do IBGE".

40. GreEn, James N. A proteção da privacidade com a abertura plena dos arquivos. Revista Acervo, vol. 24, n. 1, p. 211. 
ou produzido mentiras contidas na documentação do Dops, não é a guardiã dos documentos que é responsável por essas mentiras. A responsabilidade cai nos ombros da pessoa que produziu as mentiras ou, no caso de um historiador, jornalista, pesquisador ou cidadão, da pessoa que utilizou o material de uma maneira inapropriada." ${ }^{41}$

Por outro lado, é imperioso que se leve em conta a advertência de Troillot, no sentido de que existem vários processos na produção de história - inclusive a documental - que o profissional deve levar em conta. Primeiro, tudo que acontece não necessariamente está anotado em documentos; segundo, há um processo de silenciar o passado na criação de arquivos; terceiro, sempre existe uma arbitrariedade na decisão de quais documentos entram nos arquivos e são conservados e quais ficam de fora e são destruídos; quarto, a determinação de estabelecer um arquivo ou colecionar certos documentos e depositá-los em um arquivo é uma decisão política e não uma mera medida automática, burocrática, técnica e neutra; quinto, a narração do passado baseada em determinados documentos e com a ausência de outros vai influenciar o tipo de história produzida. ${ }^{42}$

Não bastasse isto, há a advertência fundada de James Green, no sentido de que: os documentos das forças de repressão, e aqui me refiro aos documentos da polícia política, ou seja, dos Dops, são, no seu conjunto, cheios de mentiras. Qualquer pessoa que entra nos arquivos tem que partir do pressuposto que um documento pode trazer mais decepções do que verdades, ${ }^{43}$ configurando mais uma razão para o conhecimento irrestrito de todas as fontes envolvendo a matéria.

41. Idem, p. 213

42. Trouillot, Michel-Rolph. Silencing the past: power and the production of history. Boston: Beacon Press, 1995. Ver o texto de Reis Filho, Daniel Aarão. Versões e ficções: o seqüestro da história. São Paulo: Fundação Perseu Abramo, 1997, e o texto de Huggins, Martha K.; Haritos-Fatouros, Mika; Zimbardo, Philip G. Operários da violência: policiais torturadores e assassinos reconstroem as atrocidades brasileiras. Brasília: UnB, 2006.

43. Green, James N. Op. cit. O autor explica melhor isto dizendo que: "Para quem trabalha com as fontes da polícia política e sabe bem a história da ditadura militar, isso não é novidade, mas é importante enfatizar. Sabemos que o torturador nunca vai pedir ao escrivão para botar no papel: 'depois de um interrogatório de duas horas, onde o preso ficou na cadeira do dragão trinta minutos, ele confessou tal coisa'. Existe um silêncio total a respeito da tortura nos milhões de documentos, interrogatórios, relatórios e informes produzidos pelos Dops em nível nacional. Da mesma maneira, não podemos confiar nas declarações dos presos políticos sobre as suas atividades na clandestinidade porque o jogo no interrogatório era confundir e despistar o torturador". 


\section{Considerações finals}

Para os fins de apuração da Verdade e Memória dos atos praticados pelo Estado e seus agentes em regimes de exceção, assim como das estruturas, locais, instituições e circunstâncias relacionados àquelas práticas violatórias, e suas eventuais ramificações nos diversos aparelhos estatais e na sociedade, a restrição de acesso às informações pessoais não pode ser invocada por qualquer argumento, até em respeito ao tratamento que a Lei dá aos Direitos humanos e fundamentais, individuais e sociais.

\section{REFERÊNCIAS}

Arena, Gregório. Il segreto amministrativo. Padova: Cedam, 2004.

CARrara, Sergio. Do direito de saber: o acesso à informação pessoal privada nos arquivos da ditadura militar brasileira. Revista Acervo. vol. 24. n. 1. p. 197. Rio de Janeiro: Arquivo Nacional, jan.-jun. 2011.

Cook, Michael. Liberdade de Informação: influência da prática profissional em gestão de arquivos. Revista Acervo. vol. 24. n. 1. Rio de Janeiro: Arquivo Nacional, jan.-jun. 2011.

Gentot, Michel. Access for information and protection of personal data. Commission Nationale de l'Informatique ET des Libertés. Disponível em: [http:// www.pcpd.org.hk/english/infocentre/files/gentot-paper.doc]. Acesso em: 02.03.2012.

GreEn, James N. A proteção da privacidade com a abertura plena dos arquivos. Revista Acervo. vol. 24. n. 1. p. 211. Rio de Janeiro: Arquivo Nacional, jan.-jun. 2011.

Huggins, Martha K.; Haritos-Fatouros, Mika; Zimbardo, Philip G. Operários da violência: policiais torturadores e assassinos reconstroem as atrocidades brasileiras. Brasília: Ed. UnB, 2006.

Kemoni, Harold; Wamukoya, Norbert; Kiplang'at, Jonh. Obstacles to Utilization of Information Held by Archival Institutions: a Review of Literature. Records Management Journal, 13(1).

Leal, Rogério Gesta. Verdade, memória e justiça no Brasil: responsabilidades compartidas. Porto Alegre: Livraria do Advogado, 2012.

. Estado, administração pública e sociedade: novos paradigmas. Porto Alegre: Livraria do Advogado, 2006.

(org.). A democracia deliberativa como nova matriz de gestão pública: estudo de casos. Santa Cruz do Sul: Edunisc, 2011.

Martins, Paula Ligia. Acesso à informação: um direito fundamental e instrumental. Revista Acervo. vol. 24. n. 1. p. 236. Rio de Janeiro: Arquivo Nacional, jan.-jun. 2011.

Masire, Karl. Democracy and Peace in Africa and the Role of Archives. International Journal on Archives. vol. 32. p. 87. London: Thigger, 2004. 
Mendel, Toby. Freedom of Information: a comparative legal survey. Paris: United Nations Educational, Scientific, and Cultural Organization, 2008.

Moreira Neto, Diogo de Figueiredo. Direito de participação política. Rio de Janeiro: Renovar, 1993.

Naciones Unidas. Comisión de Derechos Humanos. Conjunto de principios actualizado para la protección y la promoción de los derechos humanos mediante la lucha contra la impunidad. E/CN.4/2005/102/Add.1. 08.02.2005. Principio 3 ("El deber de recordar").

National Archives. Lord chancellor's code of practice on the management of records issued under section 46 of the Freedom of Information Act 2000. Disponível em: [www.justice.gov.uk/guidance/docs/Fol-section46-code-of-practice.pdf].

Open society justice initiative's amicus brief. [www.soros.org/initiatives/justice/litigation/chile/court-amicus-brief-3282006.pdf].

POLAKOV-SURANSKY, Sasha. The unspoken alliance: Israel's secret relationship with apartheid South Africa. New York: Pantheon, 2010.

Reis Filho, Daniel Aarão. Versões e ficções: o seqüestro da história. São Paulo: Fundação Perseu Abramo, 1997.

Shapiro, J.; Hughes, S. Information literacy as a liberal art: enlightenment proposals for a new curriculum. Educom Review, 1996. Disponível em: [www. educause.edu/pub/er/review/reviewarticles/31231.html].

SiLVA, Jaime Antunes. O centro de referência das lutas políticas no Brasil (19641985). Revista Acervo. vol. 21. n. 2. p. 14. Rio de Janeiro: Arquivo Nacional, jul.-dez. 2008.

Trouillot, Michel-Rolph. Silencing the past: power and the production of history. Boston: Beacon Press, 1995.

\section{Pesouisas do Editorial}

\section{Veja também Doutrina}

- A difícil relação entre o direito fundamental à informação e o acesso aos documentos produzidos pelo regime militar brasileiro, de Rogério Gesta Leal - RDBras 1/141;

- A tortura e o estado democrático de direito - 0 relatório da comissão especial da Lei 10.726, de 09.01.2001, de Belisário dos Santos Júnior - RBCCrim 46/289; e

- Direito à memória e reparação: da inclusão jurídica das pessoas perseguidas e torturadas na ditadura militar brasileira, de Irene Patrícia Nohara - RDCl 67/125. 